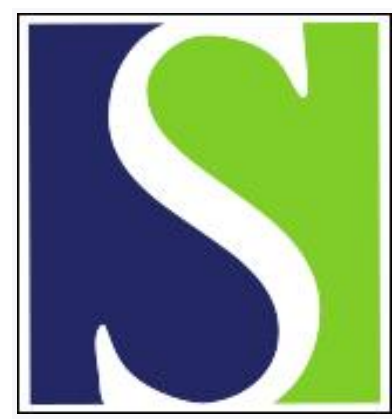

Scand J Work Environ Health 2020;46(5):457-460

https://doi.org/10.5271/sjweh.3915

Published online: 11 Aug 2020, Issue date: 01 Sep 2020

Prevention at work needed to curb the worldwide strong increase in knee replacement surgery for working-age osteoarthritis patients

by Kuijer PPFM, Burdorf A

Affiliation: Amsterdam Movement Sciences, Amsterdam UMC, University of Amsterdam, Amsterdam, The Netherlands. p.p.kuijer@amsterdamumc.nl

Refers to the following texts of the Journal: 2019;45(4):321-323 2019;45(6):546-559 2019;45(2):103-113

Key terms: arthroplasty; editorial; knee; knee osteoarthritis; knee replacement surgery; osteoarthritis; prevention

This article in PubMed: www.ncbi.nlm.nih.gov/pubmed/32780145 


\section{Prevention at work needed to curb the worldwide strong increase in knee replacement surgery for working-age osteoarthritis patients}

In the upcoming decades, hospitals and clinics around the world face a steep rise in demand from patients seeking knee replacement surgery. An absolute increase in knee replacement surgery of $297 \%$ - to 57893 procedures - is forecasted in The Netherlands between 2005 and 2030 (1). The situation is similar in many countries: Sweden, 163\% to 21700 (2013-2030) (2); Italy, 45\% to about 100000 (2017-2050) (3), the UK, 916\% to about 1.2 million (2015-2035) (4); Australia, 276\% to 65569 (2013-2030) (5); and the USA, 673\% to 3.48 million (2005-2030) (6). No projections are available for Asia, however, similar growth percentages have already been seen in Japan of $373 \%$ (2007-2014) (7) and Korea (407\%, 2001-2010) (8). Knee replacement surgery or arthroplasty is the final treatment option for patients suffering from knee osteoarthritis (OA). These increasing numbers are alarming, not only due to the extreme high demands on healthcare provision and budgets, but also for the unforeseen impact on work participation. There is a lack of awareness how work might play a significant role in reducing the steep rise in replacement surgery for knee OA across the world.

\section{Unforeseen impact on work}

The largest increase in primary surgery demands is not among the classic knee arthroplasty population of patients aged 70 years and older, but among patients of working age $(1-4,9)$. For instance, Germany - one of the leading countries in the prevalence of knee arthroplasty - foresees the highest increase in patients aged 5065 years until 2050 (10), and in a similar study using the same database even among patients aged 40-49 years until 2040 (11). In several countries, the current proportion of knee arthroplasty patients under 65 years is already substantial at $30-40 \%$. It is expected in 2030 that the USA will be the first country where the majority of these patients will be younger than 65 years (6), followed by the UK in 2035 (4).

This increase in surgery and shift towards younger age groups can largely be explained by good clinical and cost-effective long-term outcomes, no clear threshold for surgery, and the rising number of younger and more demanding knee OA patients (9). Originally, knee arthroplasty was mainly aimed at reducing pain, improving knee function and thereby enhancing the performance of activities of daily life in the patient population aged 70 years and older. The current success was totally unforeseen by LG Shiers, the founding father of knee arthroplasty (12). In 1954, he concluded: "... few surgeons will ever see 50 patients requiring arthroplasty, let alone operate on them, even in five years". Nowadays, specialized orthopedic surgeons perform this procedure several times per day. Despite the good clinical outcomes, return to work is not that favorable after surgery. About two of every ten working-age patients are dissatisfied with their work ability due to their knee arthroplasty (13). The majority of workers return to their original or other work only after six months $(13,14)$, and about three of every ten patients do not return to their original or other work after a year $(13,15)$. Especially performance of knee-demanding activities like kneeling, crouching and clambering does not improve after surgery (16).

The rapid adaptation of knee arthroplasty as preferred clinical practice for working-age knee $0 \mathrm{~A}$ patients has profound consequences for functioning at work and labor force participation. These consequences receive littleto-no attention in current clinical guidelines and yet are increasingly important outcomes for patients of working age $(17,18)$. Therefore, occupational health professionals around the world face the urgent challenge to develop evidence of how to improve a patient's ability for sustained employability - as an essential value in life - after surgery (19). Promising initiatives have recently been described although not validated for work participation yet (20-23). More importantly, occupational health professionals should play a primary role in reducing the steep increase in replacement surgery by mitigating the risk of knee $\mathrm{OA}$. 


\section{Work to reduce knee osteoarthritis and hospitalization}

Until now, little-to-no attention has been given to work as a promising point of engagement for the prevention of knee $\mathrm{OA}$ and subsequent hospitalization. A nationwide representative prospective Finnish study showed that high body mass index, prior knee injury, and an intermediate-to-high cumulative physical workload accounted for $70 \%$ of hospitalizations due to knee OA (23). Bearing these three modifiable risk factors in mind, preventive strategies at work seem warranted to reduce both the incidence of knee OA and, of course, the associated hospitalization. Primary prevention at work might mitigate all three risk factors. Without question, losing excessive body weight is key (23). Proper \& Van Oostrom (24) concluded in their review on health promotion intervention, that strong evidence exists for favorable effects of weight reduction, especially for interventions targeting diet and/or physical activity. Regarding knee injury and cumulative physical workload, reducing the time kneeling and squatting at work appears highly promising to tackle both (25-27).

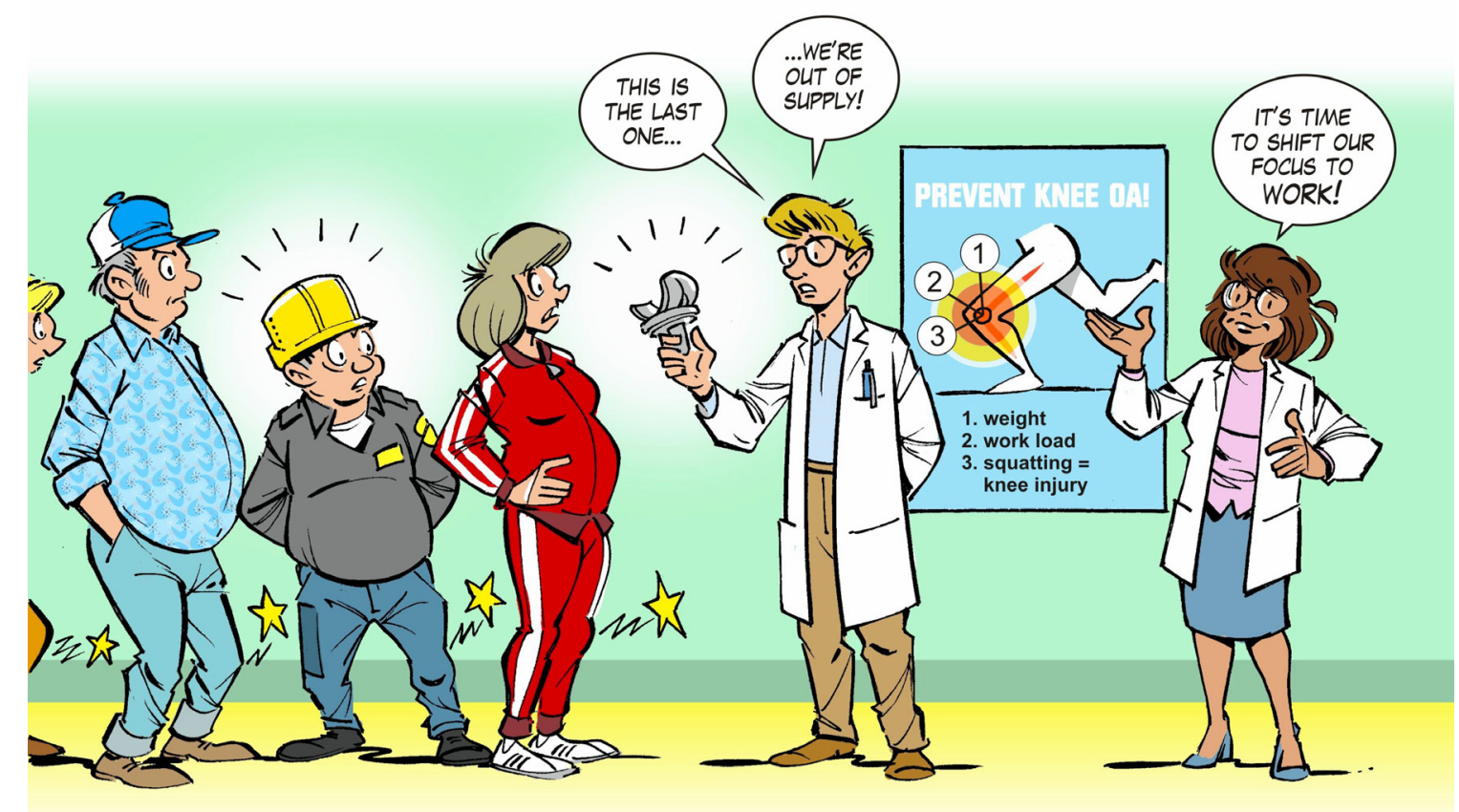

Working age knee osteoarthritis patients are especially at risk for knee replacement surgery despite the added value of work for prevention.

The upcoming EU-OSHA campaign 2020-2022 'Healthy Workplaces Lighten the Load' starting October 2020 is an excellent opportunity to focus on this specific occupational disease. Intensive interventions tailored to the specific target group are promising to reduce the risk of knee $\mathrm{OA}$ (28-30). This approach is in line with the general risk assessment strategies to safeguard workers' health and safety and, therefore, Labor Inspectorates can effectively enforce compliance with the occupational safety and health regulations (31). Moreover, the proposed combined interventions on lifestyle and workplace adaptations are also in line with the stepped-care strategy for secondary prevention of knee $O A$ (32) and of course tertiary prevention by bringing the rising hospital admission curve to its knees and thereby contributing to better health and prolonged working lives of workers at risk of "running out of cartilage". 


\section{References}

1. Otten R, van Roermund PM, Picavet HS. Trends in aantallen knie- en heupartroplastieken: de vraag naar knie- en heupprotheses blijft voorlopig toenemen [Trends in the number of knee and hip arthroplasties: considerably more knee and hip prostheses due to osteoarthritis in 2030]. Ned Tijdschr Geneeskd. 2010;154:A1534. pubmed.ncbi.nlm.nih.gov/20619009/

2. Nemes S, Rolfson O, W-Dahl A, et al. Historical view and future demand for knee arthroplasty in Sweden. Acta Orthop. 2015;86(4):426-431. doi.org/10.3109/17453674.2015.1034608

3. Romanini, E, Decarolis F, Luzi I, Zanoli G, Venosa M, Laricchiuta P, et al. Total knee arthroplasty in Italy: reflections from the last fifteen years and projections for the next thirty. Int Orthop. (SICOT). 2019;43:133-138. doi.org/10.1007/s00264-018-4165-7

4. Culliford D, Maskell J, Judge A, Cooper C, Prieto-Alhambra D, Arden NK, et al. Future projections of total hip and knee arthroplasty in the UK: results from the UK Clinical Practice Research Datalink. Osteoarthr Cartilage. 2015;23(4):594-600. doi. org/10.1016/j.joca.2014.12.022

5. Ackerman IN, Bohensky MA, Zomer E, Tacey M, Gorelik A, Brand CA, et al. The projected burden of primary total knee and hip replacement for osteoarthritis in Australia to the year 2030. BMC Musculoskelet Disord. 2019;20(1):90. doi.org/10.1186/s12891019-2411-9

6. Kurtz S, Ong K, Lau E, Mowat F, Halpern M. Projections of primary and revision hip and knee arthroplasty in the United States from 2005 to 2030. J Bone Joint Surg Am. 2007;89(4):780-785. doi.org/10.2106/JBJS.F.00222

7. Kawata M, Sasabuchi Y, Inui H, Taketomi S, Matsui H, Fushimi K, et al. Annual trends in knee arthroplasty and tibial osteotomy: Analysis of a national database in Japan. Knee. 2017;24(5):1198-1205. doi.org/10.1016/j.knee.2017.06.005

8. Koh IJ, Kim TK, Chang CB, Cho HJ, In Y. Trends in use of total knee arthroplasty in Korea from 2001 to 2010. Clin Orthop Relat Res. 2013;471(5):1441-1450. doi.org/10.1007/s11999-012-2622-y

9. Price AJ, Alvand A, Troelsen A, Katz JN, Hooper G, Gray A, et al. Knee replacement. Lancet. 2018;392(10158):1672-1682. doi. org/10.1016/S0140-6736(18)32344-4

10. Klug A, Gramlich Y, Rudert M, Drees P, Hoffmann R, Weißenberger M, et al. The projected volume of primary and revision total knee arthroplasty will place an immense burden on future heath care systems over the next 30 years. [published online ahead of print, 2020 Jul 15] Knee Surg Sports Traumatol Arthrosc. 2020;1-12. doi.org/10.1007/s00167-020-06154-7

11. Rupp M, Lau E, Kurtz SM, Alt V. Projections of primary TKA and THA in Germany from 2016 through 2040. Clin Orthop Relat Res. 2020; 478(7):1622-1633. doi: 10.1097/CORR.0000000000001214

12. Shiers LG. Arthroplasty of the knee; preliminary report of new method. The Journal of Bone and Joint surgery. British Volume. 1954;36-B(4):553-560. pubmed.ncbi.nlm.nih.gov/13211730/

13. Kievit AJ, van Geenen RC, Kuijer PP, Pahlplatz TM, Blankevoort L, Schafroth MU. Total knee arthroplasty and the unforeseen impact on return to work: a cross-sectional multicenter survey. J Arthroplasty. 2014;29(6):1163-1168. doi.org/10.1016/j. arth.2014.01.004

14. Hylkema TH, Brouwer S, Stewart RE, van Beveren J, Rijk PC, Brouwer RW, et al. Two-year recovery courses of physical and mental impairments, activity limitations, and participation restrictions after total knee arthroplasty among working-age patients. Disabil Rehabil. 2020;1-10. doi.org/10.1080/09638288.2020.1766583

15. Leichtenberg CS, Tilbury C, Kuijer PPFM, Verdegaal SHM, Wolterbeek R, Nelissen RGHH, et al. Determinants of return to work 12 months after total hip and knee arthroplasty. Ann R Coll Surg Engl. 2016;98(6):387-395. doi.org/10.1308/rcsann.2016.0158

16. Kievit AJ, Kuijer PPFM, de Haan LJ, Koenraadt KLM, Kerkhoffs GMMJ, Schafroth MU, et al. Patients return to work sooner after unicompartmental knee arthroplasty than after total knee arthroplasty. [published online ahead of print, 2019 Aug 30] Knee Surg Sports Traumatol Arthrosc. doi.org/10.1007/s00167-019-05667-0

17. Bardgett M, Lally J, Malviya A, Deehan D. Return to work after knee replacement: a qualitative study of patient experiences. BMJ Open 2016;6(2):e007912. doi.org/10.1136/bmjopen-2015-007912

18. Witjes S, van Geenen RC, Koenraadt KL, van der Hart CP, Blankevoort L, Kerkhoffs GMMJ, et al. Expectations of younger patients concerning activities after knee arthroplasty: are we asking the right questions?. Qual Life Res. 2017;26(2):403-417. doi. org/10.1007/s11136-016-1380-9

19. Coenen P, Hulsegge G, Daams JG, van Geenen RC, Kerkhoffs GM, van Tulder MW, et al. Integrated care programmes for sport and work participation, performance of physical activities and quality of life among orthopaedic surgery patients: a systematic review with meta-analysis. BMJ Open Sport \& Exercise Medicine 2020;6:e000664. doi.org/10.1136/bmjsem-2019-000664

20. Hoorntje A, Waterval-Witjes S, Koenraadt KLM, Kuijer PPFM, Blankevoort L, Kerkhoffs GMMJ, et al. Goal attainment scaling rehabilitation improves satisfaction with work activities for younger working patients after knee arthroplasty: results from the randomized controlled ACTION trial. J Bone Joint Surg Am. 2020;00:1-9doi.org/10.2106/JBJS.19.01471 
21. Straat AC, Coenen P, Smit DJM, Hulsegge G, Bouwsma EVA, Huirne JAF, et al. Development of a Personalized m/eHealth Algorithm for the Resumption of Activities of Daily Life Including Work and Sport after Total and Unicompartmental Knee Arthroplasty: A Multidisciplinary Delphi Study. Int. J. Environ. Res. Public Health 2020;17(14): 4952. https://doi.org/10.3390/ ijerph17144952

22. Coole C, Baker P, McDaid C, Drummond A. Using intervention mapping to develop an occupational advice intervention to aid return to work following hip and knee replacement in the United Kingdom. BMC Health Serv Res 2020;20:523 https://doi. org/10.1186/s12913-020-05375-3

23. Kontio T, Heliövaara M, Viikari-Juntura E, Solovieva S. To what extent is severe osteoarthritis preventable? Occupational and non-occupational risk factors for knee and hip osteoarthritis. Rheumatology (Oxford). 2020;keaa238. doi.org/10.1093/rheumatology/ keaa238

24. Proper KI, van Oostrom SH. The effectiveness of workplace health promotion interventions on physical and mental health outcomes - a systematic review of reviews. Scand J Work Environ Health. 2019;45(6):546-559. doi.org/10.5271/sjweh.3833

25. Hong CY, Lee CG, Kim DH, Cho YS, Kim KY, Ryu SY, Song HS, Workrelated risk factors of knee meniscal tears in korean farmers: a cross-sectional study. Saf Health Work. doi.org/10.1016/j.shaw.2020.05.008.

26. Rytter S, Jensen LK, Bonde JP, Jurik AG, Egund N. Occupational kneeling and meniscal tears: a magnetic resonance imaging study in floor layers. J Rheumatol. 2009;36(7):1512-1519. doi.org/10.3899/jrheum.081150

27. Verbeek J, Mischke C, Robinson R, Ijaz S, Kuijer P, Kievit A, et al. Occupational Exposure to Knee Loading and the Risk of Osteoarthritis of the Knee: A Systematic Review and a Dose-Response Meta-Analysis. Saf Health Work. 2017;8(2):130-142. doi. org/10.1016/j.shaw.2017.02.001

28. van der Beek AJ, Kunst AE. How can we break the vicious circle between poor health and exit from paid employment?. Scand J Work Environ Health. 2019;45(4):321-323. doi.org/10.5271/sjweh.3838

29. Visser S, van der Molen HF, Kuijer PP, Sluiter JK, Frings-Dresen MH. Stand up: comparison of two electrical screed levelling machines to reduce the work demands for the knees and low back among floor layers. Ergonomics. 2016;59(9):1224-1231. doi.org/ 10.1080/00140139.2015.1122233

30. Mikkelsen S, Pedersen EB, Brauer C, Møller KL, Alkjaer T, Koblauch H, Simonsen EB, Thygesen LC. Knee osteoarthritis among airport baggage handlers: A prospective cohort study. Am J Ind Med. 2019;62(11):951-960. doi.org/10.1002/ajim.23044

31. Andersen JH, Malmros P, Ebbehoej NE, Flachs EM, Bengtsen E, Bonde JP. Systematic literature review on the effects of occupational safety and health (OSH) interventions at the workplace. Scand J Work Environ Health. 2019;45(2):103-113. doi. $\operatorname{org} / 10.5271 /$ sjweh.3775

32. Smink AJ, van den Ende CH, Vliet Vlieland TP, Swierstra BA, Kortland JH, Bijlsma WJ, et al. "Beating osteoARThritis": development of a stepped care strategy to optimize utilization and timing of non-surgical treatment modalities for patients with hip or knee osteoarthritis. Clin Rheumatol. 2011;30(12):1623-1629. doi.org/10.1007/s10067-011-1835-x

\section{P. Paul F.M Kuijer, PhD}

Netherlands Center for Occupational Diseases,

Department of Public and Occupational Health, Amsterdam Public Health Research Institute, Amsterdam Movement Sciences, Amsterdam UMC, University of Amsterdam, Amsterdam, The Netherlands. [e-mail: p.p.kuijer@amsterdamumc.nl]

\author{
Alex Burdorf, PhD \\ Department of Public Health, Erasmus Medical Center, \\ Rotterdam, The Netherlands \\ [Email: a.burdorf@erasmusmc.nl]
}

